\title{
Wear behavior of Diamond-like Carbon Deposited on Ti6Al4V Prepared with Surface Mechanical Attrition Treatment
}

\author{
Luciane Yumi Suzuki de Oliveira ${ }^{a}$, Carlos José Mesquita Siqueira ${ }^{b}$, Beatriz Luci Fernandes ${ }^{a}{ }^{\circledR}$, \\ Neide Kuromoto ${ }^{c}$, Delphine Retraint ${ }^{d}(\mathbb{B}$
}

\author{
aPrograma de Pós-Graduação em Tecnologia em Saúde, Escola Politécnica, Pontifícia Universidade \\ Católica do Paraná (PUCPR), 80215-901, Curitiba, PR, Brasil \\ ${ }^{b}$ Departamento de Engenharia Mecânica, Universidade Federal do Paraná (UFPR), 81531-980, \\ Curitiba, PR, Brasil \\ ${ }^{c}$ Departamento de Física, Universidade Federal do Paraná (UFPR), 81531-980, Curitiba, PR, Brasil \\ ${ }^{d}$ Charles Delaunay Institute (ICD), Physics, Mechanics, Material and Nanotechnology Department, \\ LASMIS, University of Technology of Troyes (UTT), 10004 TROYES Cedex, France
}

Received: August 15, 2018; Revised: December 02, 2018; Accepted: December 05, 2018

\begin{abstract}
Surface modification by deposition of hard coatings is a way to overpass the poor wear resistance of some metallic materials and one potential material is the Diamond-Like Carbon (DLC). We investigated the wear behavior, and the adhesion of the DLC deposited on a Ti6Al4V (Ti64) alloy after Surface Mechanical Attrition Treatment (SMAT). The SMAT was applied using 100Cr6 steel balls, and the DLC was deposited through the sputtering method. The nano-hardness was evaluated using a MTS Nano Indenter XP. The adhesion of the DLC was evaluated using a CSM Revetest, and the wear tests were performed in a reciprocating linear tribometer from CSM Instruments. The mean wear rate for the Ti64 was $437 \times 10^{-6} \mathrm{~mm}^{3} / \mathrm{N} / \mathrm{m}$ against $5 \times 10^{-6} \mathrm{~mm}^{3} / \mathrm{N} / \mathrm{m}$ for the Ti64+SMAT+DLC. The SMAT reduced the wear rate of the DLC coating, showing that the SMAT might be a viable treatment with promising results regarding the DLC wear resistance.
\end{abstract}

Keywords: Ti6Al4V, DLC coating, SMAT on Ti6Al4V surface.

\section{Introduction}

Ti-based alloys are considered bioinert and biocompatible, and due to its low density, low Young's modulus and high corrosion resistance, are widely used in the manufacturing of orthopedic implants. Among the Ti-based alloys, the Ti6Al4V is the most used because of its interesting properties like strength-to-weight ratio, corrosion resistance, and toughness ${ }^{1}$. However, the Ti6Al4V has poor wear resistance and low hardness ${ }^{1}$ avoiding its use in parts exposed to the sliding movement as in joint prosthesis. Surface modification techniques are used to overpass this undesirable property and, among them, the deposition of a hard material is a viable process.

Diamond-Like Carbon (DLC) is a strong candidate for coating on Ti6Al4V due to its high hardness, low coefficient of friction and chemical stability ${ }^{2}$. The wear resistance of the DLC reduces drastically the amount and size of the wear debris minimizing the possibility of the aseptic loosening of the prosthesis.

One of the problems with the DLC coating is its adhesion to the substrate that usually has a low level of reliability ${ }^{3}$. Surface modification of the substrate is an alternative to improve the adhesion between the materials, and among the techniques available, there is the Surface Mechanical
Attrition Treatment (SMAT) that creates a nano-crystallized surface layer ${ }^{4}$. Due to the multiple impacts of spheres, the grain size is refined, and the residual stresses are reduced on the surface and subsurface ${ }^{5}$. Since it has an exclusively mechanical nature, there is no change in the chemical composition of the surface of the treated material ${ }^{6,7}$.

The objective of the present work was to evaluate the wear behavior, and adhesion of the DLC deposited on a Ti6A14V alloy previously submitted to SMAT.

\section{Material and Methods}

\subsection{Discs preparation}

The Ti6A14V alloy (ASTM F136) supplied by Vulcanium Technology, was cut in discs with $15.88 \mathrm{~mm}$ diameter and $5 \mathrm{~mm}$ thickness. The composition was confirmed by X-Ray Spectrometry in wt\%: $0.006 \mathrm{C} ; 0.0037 \mathrm{H} ; 0.1151 \mathrm{O} ; 0.0066$ $\mathrm{N} ; 6.13 \mathrm{Al} ; 0.18 \mathrm{Fe} ; 3.97 \mathrm{~V}$ and balance Ti. Twenty-one discs were grounded and polished to achieve mirror-like surface, according to the steps reported in the previous work ${ }^{2}$. The polished discs, with a surface roughness (Ra) of $0.040 \pm$ $0.013 \mu \mathrm{m}$, were cleaned with aqueous acetone solution in an ultrasonic bath and air-dried. 


\subsection{SMAT procedure}

The SMAT was performed at the Université de Technologie de Troyes in the Institut Charles Delaunay Laboratory, France, using parameters chosen based on the experience of the research group in that kind of surface treatment. The SMAT was applied at the center of 54 discs covering an area of about $113.04 \mathrm{~mm}^{2}$, using $2 \mathrm{~mm}$ diameter $100 \mathrm{Cr} 6$ steel balls (AISI 52100) set in motion by an ultrasonic generator (20 kHz frequency). The treatment lasted 15 minutes and the surface roughness (Ra) measured was $0.720 \pm 0.076 \mu \mathrm{m}$.

\subsection{DLC coating}

Before the deposition of DLC, 27 of the discs from the SMAT procedure were cleaned with acetone in an ultrasonic bath. The sputtering method was performed in an atmosphere composed of Argon, Acetylene and Nitrogen, and Carbon, and Ti cathodes as solid sources. The multilayer deposition parameters that guaranteed the DLC deposition ${ }^{8}$ were: temperature between $180{ }^{\circ} \mathrm{C}$ and $200{ }^{\circ} \mathrm{C}$, a bias voltage of $-400 \mathrm{~V}$, sputtering power of $5 \mathrm{~kW}$, and total deposition time between 10 and $15 \mathrm{~h}$. It was obtained layer thickness from 2 to $3 \mathrm{~mm}$. The final surface roughness (Ra) was $1.150 \pm 0.147 \mu \mathrm{m}$.

\subsection{Characterization of the SMAT and DLC coatings}

The nano-hardness of the discs from the groups TiAl4V alone, Ti6Al4V+SMAT, and Ti6Al4V+SMAT+DLC were evaluated using a MTS Nano Indenter XP with a Berkovich diamond tip, having the maximum load of $400 \mathrm{mN}$ during $15 \mathrm{~s}$ with nine indentations distant $100 \mu \mathrm{m}$ each other, and with a maximum depth of $2.25 \mathrm{~nm}$. Three discs of each group were tested.

The adhesion resistance of the DLC coating was evaluated using a CSM Revetest with a Rockwell C diamond tip (400 $\mu \mathrm{m}$ diameter) on three discs of each group. The load between $5 \mathrm{~N}$ and $60 \mathrm{~N}$ and scratch length of $8.0 \mathrm{~mm}$ lasted about 3 minutes.

The tribological test had been performed in a reciprocating linear tribometer from CSM Instruments on a ball-on-disk configuration and in dry air. Five discs of each group were sliding against $6.0 \mathrm{~mm}$ diameter tungsten carbide ball with the parameters: a load of $5 \mathrm{~N}$ for Ti6 Al4V without coating, a load of $10 \mathrm{~N}$ for DLC coating, the frequency of $2 \mathrm{~Hz}$, the amplitude of $4.0 \mathrm{~mm}$, and 5,000 cycles $^{2}$. It was performed three scratches in each sample. The wear rate and the transversal section area were obtained by the Tribox Software (v.2.0) from CSM Instruments.

\section{Results and Discussion}

It would be expected that the SMAT produced a higher surface roughness on the Ti6Al4V samples since that generates random directional ball impacts causing superficial plastic deformations. According to Arifvianto et al. (2011), although SMAT surface depends on the parameters of the treatment, it increases about 20 times the surface roughness of the substrate and changes the geometric surface properties. The parameters applied herein caused an increase of about 18 times on the surface roughness of the Ti6Al4V sample, measured in horizontal, vertical, and $45^{\circ}$ directions. The increasing of the roughness is attributed to the heights of peaks and valleys formed on the treated surface.

The DLC roughness measurements show a higher value $(1.150 \pm 0.147 \mu \mathrm{m})$ than that for Ti6Al4V+SMAT $(0.720 \pm$ $0,076 \mu \mathrm{m})$. Especially for DLC coatings, high content of $\mathrm{sp}^{2}$ (graphite) clusters increases the roughness ${ }^{9}$. A previous work ${ }^{2}$ showed by Raman spectroscopy that the coating formed and used in the present work has almost the same amount of $\mathrm{sp}^{3}$ and $\mathrm{sp}^{2}$ clusters, explaining the higher roughness compared to the substrate. There is a suggestion that the increase in graphitic clusters is related to its diffusion to the surface of the coating as the deposit become thicker, as well as to the deposition temperature, generally higher than $300^{\circ} \mathrm{C}{ }^{10}$. It is known that the coatings with high intrinsic roughness produce rougher surfaces than those of the substrates. Therefore, for smoother surfaces, the substrates must have a larger roughness than the film ${ }^{11}$.

The average indentation hardness measured for the samples of Ti6Al4V without surface treatment was $3.5 \mathrm{GPa}$ that is approximately the value of the average nano-hardness of the same alloy described by Arslan et al. (2013) of 4.0 $\mathrm{GPa}$, although the hardness is related to the thermal history during the manufacturing process. As expected, the nanohardness of the SMAT surface, $4.3 \mathrm{GPa}$, was higher than that of the Ti alloy, because during the SMAT the balls impacts refine the grains size to a nanometer scale inducing residual stress at the work surface ${ }^{9}$. Therefore, the reduction of the grains size together with the residual stress increases the surface hardness. The average nano-hardness of the DLC coating was very low ( $3.5 \mathrm{GPa})$, the same value measured in the substrate. Since the maximum displacement during the nanoindentation was $2.25 \mathrm{~nm}$, it respected the general practice of maintaining the depth inferior to $20 \%$ of the coating thickness to minimize the influence of the substrate ${ }^{12}$.

Consequently, the nano-hardness measured was that of the DLC coating. The amorphous DLC coatings can be divided into hydrogenated carbon amorphous or tetragonal one (a-C:H; ta-C:H) and a harder non-hydrogenated carbon also amorphous or tetragonal (a-C; ta-C). The hydrogen content depends on the coating process, usually using hydrocarbon gas such as methane or acetylene as a precursor ${ }^{13}$. In the present work, the acetylene was part of the gas mixture for DLC deposition; therefore, the hydrogenated type is expected to form. Softer DLC coating has from 40 to $50 \%$ of hydrogen ${ }^{14}$, and the low nano-hardness suggests graphitization as observed in the Raman spectroscopy in the previous work ${ }^{2}$. 
The objective of the scratch test was to evaluate the adhesion of the DLC coating through the measurement of the load required to detach the film. The first cracks and delaminations occur in critical loads that are used for the comparative adhesion evaluation. Figure 1 shows the MEV segmented images of the scratch tracks.

In Figure 1, it is possible to identify the bending cracks that are the primary failure types for DLC coating thickness from $1.0 \mathrm{~mm}$ to $3.0 \mathrm{~mm}$. The scratch test performed on a hard material deposited on a ductile one (DLC on Ti6Al4V), promotes the coating failure mainly due to extensive plastic deformation of the substrate. The bending cracks at the center of the track are responsible for the adhesion failure of the coating and are caused by the plastic deformation of the substrate and by the tensile stress in front of the indenter. The inclined hair cracks at the edge of the track are formed ahead of the sliding indenter contributing for the coating detachment ${ }^{15}$.

Evaluating the adhesion of DLC (ta-C) coating, $3 \mathrm{~mm}$ thickness on steel substrate, found critical loads between $10 \mathrm{~N}$ and $22 \mathrm{~N}^{15}$. In the present work, the critical load was 21 N. However, the critical loads depend on the substrate material and the test parameters, besides the coating thickness. Therefore, to be comparable with results from other works, all the parameters should be identical. Besides, the critical load does not indicate the extension and mode of the adhesive or cohesive failure ${ }^{15}$. Thus, image evaluation of scratch tests performed using different parameters of the deposition process is more valuable than the critical load itself.

The average wear rate for the Ti6Al4V without coating was $437 \times 10^{-6} \mathrm{~mm}^{3} / \mathrm{N} / \mathrm{m}$ while for the Ti6Al4V+SMAT+DLC was $5 \times 10^{-6} \mathrm{~mm}^{3} / \mathrm{N} / \mathrm{m}$, represented in Figure 2. Despite the huge difference, the comparison between these values is difficult because, unlike bulk materials, wear test of thin films (up to $3 \mathrm{~mm}$ ) is limited to $80 \%$ of their thickness to avoid the influence of the substrate or bonding layers, which produces a very low volume of debris ${ }^{16}$. However, Oliveira et

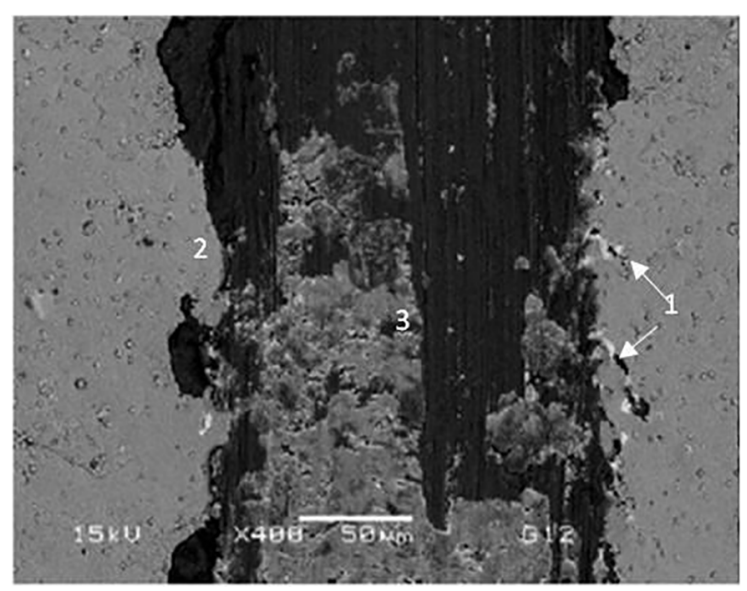

Figure 1. MEV of the scratch tracks of the DLC deposited on Ti6Al4V + SMAT. Details of the (1) hair cracks; (2) delamination at the edge and (3) bending cracks ${ }^{16}$.

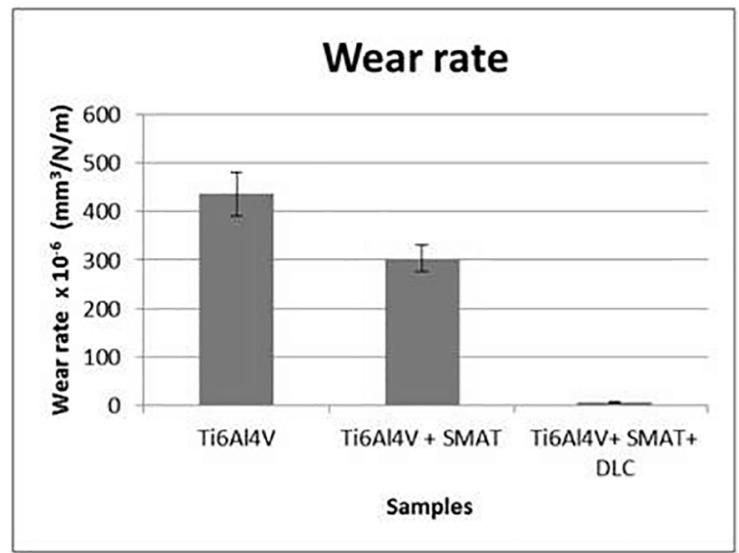

Figure 2. Wear rate of the samples. SMAT improved the wear rate of the Ti6A14V alloy by approximately $25 \%$.

al., 2014, using the same parameters for the DLC deposition on Ti6A14V without SMAT, and the same configuration and parameters for the wear test, found an average wear rate of $12 \times 10^{-6} \mathrm{~mm}^{3} / \mathrm{N} / \mathrm{m}$. Therefore, the SMAT reduced the wear rate of the DLC coating.

It is known that one of the parameters related to the DLC coating durability is the adhesion to the substrate ${ }^{17}$. Vladimirov et al., (2000), suggested that the ratio between the roughness of the substrate and the thickness of the deposited film from 0.2 to 0.3 , leads to the minimum wear rate. In the present work, the ratio was 0.29 , and for Ti6Al4V+DLC from Oliveira et al., 2014, the ratio was 0.02. According to these criteria, it is expected that the SMAT improves the wear resistance and the competing between the roughness of the substrate and the coating thickness seems to define the adhesion resistance and the tribological behavior of the film. Figure 3 shows the wear track of the samples.

Besides the surface roughness, phase transformation influences the wear performance of the DLC coating and occurs when high contact pressures or frictional heating, or both, are present on friction condition. On the first contact, the surface asperities can fracture or phase transforming to graphitic form, the more stable form of carbon. The graphitic debris accumulates gradually at the sliding tracks negatively affecting the wear performance of the DLC ${ }^{18}$.

The coefficient of friction (COF) of the TiAl4V alone, Ti6A14V+SMAT, and Ti6A14V+SMAT+DLC is presented in Figure 4.

As one can see, the COF for the TiAl4V alone (from 0,4 to 0,45 ) and the Ti6Al4V+SMAT (from 0,35 to 0,40 ) are higher than that for the DLC coated $(0,20)$. The increasing value of the COF for the TiAl4V and the Ti6Al4V+SMAT groups can be explained by the tribological characteristic of a dry sliding system like that presented herein. During sliding against WC, the Ti6Al4V alloy undergoes plastic deformation and the release of wear debris of Ti, $\mathrm{Al}$, and $\mathrm{V}$ at the interface between the two materials causes severe abrasive wear, increasing the $\mathrm{COF}^{2,19}$. The oscillation between the 

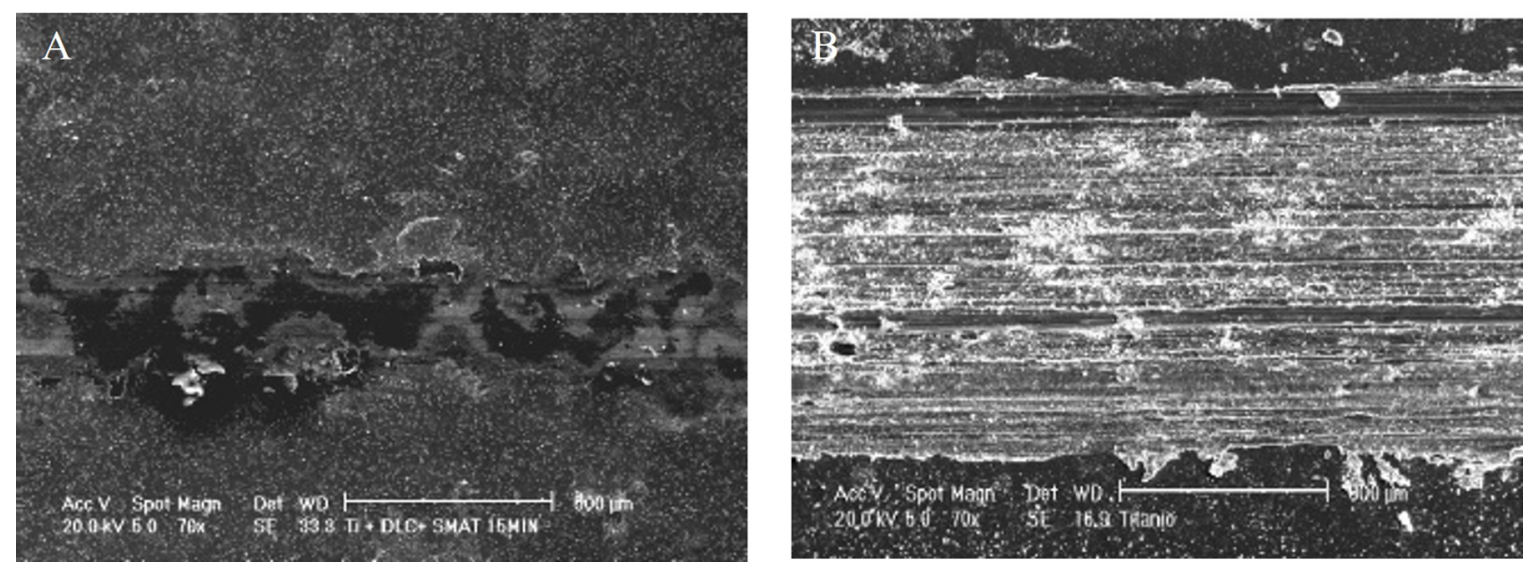

Figure 3. Wear track of the samples: (A) Ti6Al4V alloy, (B) Ti6Al4V + SMAT + DLC.

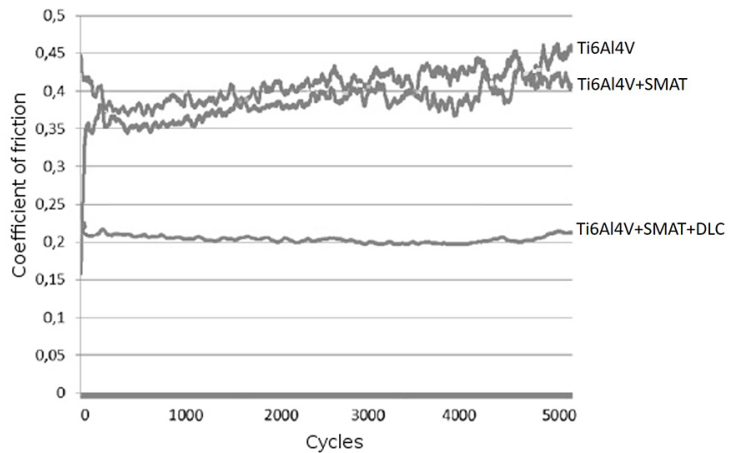

Figure 4. The coefficient of friction of the samples: Ti6Al4V, Ti6Al4V+SMAT, and Ti6Al4V+SMAT+DLC.

minimum and maximum COF values is a typical third body effect ${ }^{20}$. The low COF for the DLC coating in dry sliding systems can be attributed to the transformation of the DLC into a graphite-like state, which is a lubricant material, as a result of the sliding action. Also, hydrogenated DLC coating can transfer a carbon layer from the DLC to the opposing surface, and when DLC coating slides against DLC coating, the $\mathrm{COF}$ reduces ${ }^{21}$.

Despite the excellent tribological features of the DLC coatings in vitro tests, the ten years follow-up study of patients with DLC coated femoral head, developed by Taeger et al. $(2003)^{22}$, showed a high mechanical failure rate (45\%) attributed to the poor adhesion to the substrate. In this sense, the SMAT can contribute to improve the adhesion resistance, and consequently, minimize the aseptic loosing of the joint prosthesis.

\section{Conclusions}

Diamond-like carbon coatings are known for increasing wear resistance in surfaces submitted to constant friction. Their poor adherence to the substrate can prevent the use of such coating in surgical components. Pre-treatment that modifies the surface of the Ti6Al4V before the coating deposition can overcome such limitation and SMAT might be a viable treatment with promising results.

\section{Acknowledgments}

The authors would like to thank Dr. Bruno Guelorget for the support on nano-indentation tests, Dr. Ronaldo Ruas, from Brasimet Bodycote, for the DLC deposition; Irineu Vitor Leite and Dr. Geninho Thomé, from Neoortho Produtos Ortopédicos for the Ti6Al4V samples; LabNano and CME from UFPR for hardness tests and MEV images.

\section{References}

1. Bai LL, Li J, Chen JL, Song R, Shao JZ, Qu CC. Effect of the content of $\mathrm{B} 4 \mathrm{C}$ on microstructural evolution and wear behaviors of the laser-clad coatings fabricated on Ti6Al4V. Optics \& Laser Technology. 2016;76:33-45.

2. De Oliveira LYS, Kuromoto NK, Siqueira CJM. Treating orthopedic prosthesis with diamond-like carbon: minimizing debris in Ti6A14V. Journal of Materials Science: Materials in Medicine. 2014;25(10):2347-2355.

3. Horiuchi T, Yoshida K, Kano M, Kumagai M, Suzuki T. Evaluation ofAdhesion and Wear Resistance of DLC films Deposited by Various Methods. Plasma Process and Polymers. 2009;6(6-7):410-416.

4. Kavitha C, Ravichandran K, Sankara Narayan TSN. Effect of surface mechanical attrition treatment (SMAT) on zinc phosphating of steel. Transactions of the IMF. 2014;92(3):161-168.

5. Zhu KY, Vassel A, Brisset F, Lu K, Lu J. Nanostructure formation mechanism of a-titanium using SMAT. Acta Materialia. 2004;52(14):4101-4110.

6. Laleh M, Kargar F. Formation of high bioactive nanoporous titanium film by hybrid surface mechanical attrition treatment. Materials Letters. 2011;65(14):2295-2298. 
7. Roland T, Retraint D, Lu K, Lu J. Enhanced mechanical behavior of a nanocrystallised stainless steel and its thermal stability. Materials Science and Engineering: A. 2007;445446:281-288.

8. Pancielejko M, Czyzniewski A, Zavaleyev V, Pander A, Wojtalik K. Optimization of the deposition parameters of DLC coatings with the MCVA method. Archives of Materials Science and Engineering. 2012;54(2):60-67.

9. Arifvianto B, Suyitno, Mahardika M, Dewo P, Iswanto PT, Salim UA. Effect of surface mechanical attrition treatment (SMAT) on microhardness, surface roughness and wettability of AISI 316L. Materials Chemistry and Physics. 2011;125(3):418-426.

10. Peng XL, Barber ZH, Clyne TW. Surface roughness of diamond-like carbon films prepared using various techniques. Surface and Coatings Technology. 2001;138(1):23-32.

11. Spiller E, Baker S, Parra E, Tarrio C. Smoothing of Mirror Substrates by Thin-Film Deposition. In: Proceedings of the 44th SPIE - International Symposium on Optical Science, Engineering, and Instrumentation; 1999 Jul 18-23; Denver, CO, USA. p. 1-11.

12. Zhang TH, Huan Y. Nanoindentation and nanoscratch behaviors of DLC coatings on different steel substrates. Composites Science and Technology. 2005;65(9):1409-1413.

13. Alakoski E, Tiainen VM, Soininen A, Konttinen YT. LoadBearing Biomedical Applications of Diamond-Like Carbon Coatings - Current Status. The Open Orthopaedics Journal. 2008;2:43-50.

14. Al Mahmud KAH, Kalam MA, Masjuki HH, Mobarak HM, Zulkifli NWM. An updated overview of diamond-like carbon coating in tribology. Critical Reviews in Solid State and Materials Sciences. 2015;40(2):90-118.
15. Zawischa M, Makowski S, Schwarzer N, Weihnacht V. Scratch resistance of superhard carbon coatings - A new approach to failure and adhesion evaluation. Surface and Coatings Technology. 2016;308:341-348.

16. Novak R, Polcar T. Tribological analysis of thin films by pin-ondisc: Evaluation of friction and wear measurement uncertainty. Tribology International. 2014;74:154-163.

17. Vladimirov AB, Trakhtenberg IS, Rubshtein AP, Plotnikov SA, Bakunin OM, Korshunov LG, et al. The effect of substrate and DLC morphology on the tribological properties coating. Diamond and Related Materials. 2000;9(3-6):838-842.

18. Tambe NS, Bhushan B. Nanoscale friction-induced phase transformation of diamond-like carbon. Scripta Materialia. 2005;52(8):751-755.

19. Živić F, Babić M, Mitrović S, Todorović P. Interpretation of the Friction Coefficient During Reciprocating Sliding of Ti6Al4V Alloy Against $\mathrm{Al}_{2} \mathrm{O}_{3}$. Tribology in Industry. 2011;33(1):36-42

20. Bartolomeu F, Buciumeanu M, Pinto E, Alves N, Silva FS, Carvalho O, et al. Wear behavior of Ti6Al4V biomedical alloys processed by selective laser melting, hot pressing and conventional casting. Transactions of Nonferrous Metals Society of China. 2017;27(4):829-838.

21. Gangopadhyay A, Sinha K, Uy D, McWatt DG, Zdrodowski RJ, Simko SJ. Friction, Wear, and Surface Film Formation Characteristics of Diamond-Like Carbon Thin Coating in Valvetrain Application. Tribology Transactions. 2011;54(1):104-114.

22. Taeger G, Podleska LE, Schmidt B, Ziegler M, Nast-Kolb D. Comparison of Diamond-Like-Carbon and Alumina-Oxide Articulating with Polyethylene in Total Hip Arthroplasty. Materialwissenchaft und Werkstofftechnik. 2003;34(12):10941100 . 